\title{
As máscaras de dança cokwe na perspectiva de uma estética africana
}

\author{
Ana Clara Guerra Marques
}

\begin{abstract}
RESUMO: O ARTIGO CONSTITUI UMA APROXIMAÇÃO À TEMÁTICA DAS MÁSCARAS DE DANCCA COKWE, SITUANDO-AS NO CONTEXTO ARTÍSTICO AFRICANO DE UMA DADA REGIÃO - MAIS PROPRIAMENTE NO TERRITÓRIO OCUPADO PELOS POVOS BANTU - E FOCANDO-AS NO EIXO DE ALGUNS PRINCÍPIOS PARA A DEFINICCÃO DE UMA ESTÉTICA AFRICANA.
\end{abstract}

ABSTRACT: THE PAPER CONSTITUTES AN APPROACH TO THE THEMATIC OF DANCE MASKS COKWE, PLACING THEM ON THE AFRICAN ARTISTIC CONTEXT OF A CERTAIN REGION MORE PROPERLY IN THE OCCUPIED TERRITORY BY BANTU PEOPLE - AND FOCUSING THEM IN THE AXLE OF SOME PRINCIPLES FOR THE DEFINITION OF AN AFRICAN AESTHETIC.

PALAVRAS-CHAVE: CORPO, ESTÉTICA AFRICANA, MÁSCARA, RITUAL, FUNCIONALIDADE KEY-WORDS: BODY, AFRICAN AESTHETIC, MASK, RITUAL, FUNCTIONALITY. 


\section{Questões e Contextos}

Expressões relativamente vulgarizadas como «arte africana»e «estética africana» devem, na nossa perspectiva, ser adoptadas com reservas. O grau de generalização destas expressões convida ao nivelamento do território, à subestimação das diferenças e a uma redução da realidade. Não obstante estes factos, elas serão aqui utilizadas não só por manterem a sua validade no meio académico, mas porque remetem para uma área de apreciação concreta: a arte na zona geográfica da África a sul do Sahara (África central). Com efeito, embora a ideia de definir uma identidade africana seja controversa, pode dizer-se que existe algo de «especificamente africano», passível de ser geograficamente circunscrito-Portanto, a presença incontornável de um significativo conjunto de elementos partilhados na arte produzida nesta região de África pode, igualmente, pressupor a presença de estéticas com um profundo radical comum.

No âmbito dos estudos académicos, os estudos sobre Estética africana são relativamente recentes. Na sua obra African Aesthetics (1986), Susan Vogel centra-se na estética e na sua precisão enquanto linguagem africana, apresentando exemplos detalhados de estéticas africanas; R. F. Thompson (1979), a partir da cultura Yoruba, define alguns princípios básicos para a definição de uma estética africana; enquanto D. Biebuyck (1983) e M. Adams (1989) se dedicam a abordagens da arte africana numa perspectiva histórica, B. Wastiau (2003) articula as questões do estilo e da etnicidade e W. MacGaffey (2000) interessa-se pelas relações entre a estética e a política em África.

Integradas num sistema filosófico tradicional suportado por importantes práticas religiosas, as máscaras de dança cokwe, enquanto mediadoras e representantes de um saber ancestral, exibem-se marcadas por inscrições diversas que longe de serem meramente decorativas, constituem um sistema simbólico que as vinculam à cosmologia deste povo.

No plano da arte africana, os Tucokwe', há muito ocupam um lugar de destaque. Tendo deixado fortes marcas da sua presença nas zonas por onde passaram durante os grandes movimentos migratórios desde o século XVI, oferecem hoje,

1 Povo de origem bantu radicado na região Nordeste de Angola, mas também na Zâmbia e na República Democrática do Congo. 
fundamentalmente a nível da escultura e danças de mascarados, objectos para o estudo da arte africana. Porém, a possibilidade de se falar de uma estética cokwe não significa, em absoluto, o alargamento das suas especificidades a todo o contexto africano. Digamos que as suas influências integram o conjunto de pontos de convergência que se destacam no vasto conjunto de povos desta região.

As noções de um «belo» padronizado, mais ou menos generalizadas no mundo ocidental (progressivamente questionadas por alguns autores), conhecem nestes contextos outras atribuições que articulam o lado funcional das peças produzidas com uma preocupação e investimento no campo da estética manifestadas no acto da criação.

Com efeito, e embora frequentemente se remeta a questão da arte africana para o simples utilitarismo, pode afirmar-se, sem reservas, que existe uma intencionalidade artística perceptível e visível na complexidade de ideias e objectivos, bem como no «encantamento» produzidos. Como refere Wastiau (2003, p. 50), "Any object has a sign and agency value that primes over its pedestrian use value, and this is specially true in the case of works of art because they embody intentionality.» Consequentemente, o mesmo autor demarca a diferença entre o artesão e o artista ao referir que «the artist could be distinguished as s/he who as a role to work on social relationships via the object she/he has craft witch brings about the emergency of a belief in the mystical and the magical power of his/her object and his/her person.» (ibidem), o que se verifica relativamente aos mascarados, ou akixi, enquanto intermediários entre duas realidades.

Estes mascarados podem ser vistos como corpos que revelam claramente outros corpos. Os bailarinos que envergam as máscaras, não se escondem dentro delas; pelo contrário, expõem a vontade e a personalidade de um ancestral, transformando-se no suporte que permite a essa máscara «aparecer» e exprimir-se, integrando-a e tornando-a acessível à comunidade. Por isso, a sua aparência e fisionomia se desviam e, simultaneamente, se aproximam dos padrões humanos.

As suas performances (tal como as esculturas) valem não apenas pelo que são no seu aspecto formal, mas principalmente pela função que lhes é inerente: intervir (modificar) na vida moral e espiritual dos indivíduos, enriquecendo, com o seu significado simbólico, o curso da sua existência quotidiana.

Portanto, também neste caso se torna fundamental que não se dissocie o conceito de arte deste agenciamento social, despindo os julgamentos estéticos 
de qualquer subjectividade pessoal ou predefinição institucional. Para uma melhor integração e gestão de todos estes princípios será imprescindível olhar a arte africana a partir de conceitos e padrões estabelecidos internamente por essas culturas. Dando espaço para que falem por elas próprias, consegue-se uma visão local, mais específica e menos comparada aos arquétipos ocidentais que ao longo dos tempos têm vindo a influenciar uma significativa parte dos estudos produzidos.

A propósito da cultura Baulé (mas abrindo a constatação à generalidade dos povos desta região), Susan Vogel (1997) defende que o conceito de «objecto de arte», por exemplo, tal como é entendido no Ocidente, não existe, já que o termo «arte» não consta dos léxicos da maioria das línguas africanas e os objectos criados não pressupõem a existência de um público fruidor.

Nestas realidades, a arte é fortemente comprometida e determinada pelas expressões rituais e religiosas, bem como pelos indicadores do carácter dos povos ou sociedades. Outros factores de influência são o meio ambiente e respectiva história, bem como o facto de se tratar de sociedades sem um sistema de escrita convencional. A presença constante das suas cargas ancestrais é absolutamente indissociável de qualquer interpretação ou produção artística entre os povos bantu.

\section{Importância, função e significado da máscara}

Para além de constituir um distintivo de classe ou de papel social, a máscara é, igualmente, factor de delimitação dos territórios do género e das distintas etapas da vida.

Por outro lado, ela serve o desejo do ser humano se transcender para aceder à experiência de outras existências, aumentando o seu próprio poder e identificando-se com as forças do universo.

Entre os povos bantu, as máscaras são, como referido, objecto de evocação e realização de uma acção dos antepassados ${ }^{2}$ ou dos génios entre os homens,

2 No plano religioso, os Tucokwe acreditam num ente superior - Deus (Nzambi ou Kalunga) - representante da vida, mas uma grande importância é atribuída ao culto dos ancestrais. 
atribuindo-se o seu surgimento a razões de ordem sócio-religiosa, motivadas pelo culto dos ancestrais. A instituição das máscaras nesta região é organizada segundo a cosmologia de cada grupo social ${ }^{3}$, numa rede de vários elementos, cada um dos quais ocupando um lugar num sistema geral de correlação de acontecimentos que se revelam de forma simbólica durante as suas actuações.

Para os Tucokwe, a máscara não é, portanto, um acessório teatral ou um mero objecto decorativo ou figurativo. Mascarar-se não significa uma simples operação de modificação. "Os Tshokwe utilizam a palavra mukishi (pl. akishi) para referir um espírito ancestral ou da natureza que é encarnado por uma máscara.» (Bastin, 1999, p. 95)

Efectivamente, Américo Kwononoka ${ }^{4}$, informou-nos que o termo mukixi (pl. akixi) designa um ser que encarna um monstro surgido da terra, derivando da palavra Cikixikixi que significa, em língua cokwe, gigante extraterrestre ${ }^{5}$.

O termo mukixi é, igualmente, utilizado para designar as danças de mascarados, as máscaras de dança e os bailarinos mascarados.

Ao afirmar que os «Makishi often serve to sanction and validate social and political institutions, which are generally perceived as the domain of men.»e que «(...) they may also appear during annual confirmatory ceremonies for chiefs», Jordán (1998, p. 67) confirma o vínculo da máscara quer às estruturas sociais ${ }^{6}$, quer às estruturas do poder, reforçando que a sua acção se estende para além da espiritualidade.

Com um papel interventivo e actuante dentro da sociedade cokwe, os akixi são a representação destes ancestrais que retornam à terra «to guide, assist, protect, and even educate members of a community on important occasions.» (ibidem, p. 67)

Pela máscara, o seu utilizador tem a possibilidade de participar da multiplicidade da vida, criando novas realidades, exteriores às da sua condição humana,

\footnotetext{
3 Os Tucokwe não estão organizados em tribo, mas em sobados, possuindo cada aldeia os seus próprios orgãos de poder. O elemento fundamental da existência individual e social deste povo é a comunidade, sendo a família o núcleo da sua estrutura social.

4 Entrevistado pela autora em Luanda em 1987.

5 Quando há uma cerimónia para a qual se convocam as máscaras, diz-se aos mais impacientes e curiosos que "akixi kanavumbuka" (os mascarados estão ressuscitando).

6 Como um exemplo, temos o paralelo que se estabelece com o sistema de hereditariedade (segundo gerações de filiação matrilinear) quando o sobrinho herda a máscara do tio, irmão da mãe.
} 
o que representa a possibilidade de uma outra forma de existir, admitida e reconhecida pelo colectivo.

Assim, o seu estatuto deve ser secreto, pois perante a sociedade os akixi não são reconhecidos como humanos, devendo manter a sua identidade oculta. $\mathrm{Na}$ comunidade, acredita-se no poder transfigurador da máscara, perante a qual mulheres e crianças fogem atemorizadas, evidenciando um sentimento situado entre o medo e o respeito, relativamente a estas figuras.

Decorrentes da sua pluralidade de funções, existem diversas propostas de classificação para as quais vários autores ${ }^{7}$ consideram distintos critérios de selecção. No nosso caso, interessou tomar como critério taxonómico a relação das máscaras com a dança, tendo-se definido dois grupos: as máscaras que dançam e as máscaras que não dançam. Excluindo este segundo grupo, destacamos dentre aquelas que o fazem, as máscaras que subsistem enquanto profissionais, exibindo-se em performances que, para além da dança e da música, podem incluir teatralizações, anedotas, provérbios e canções. Entre outras máscaras dançadas por bailarinos profissionais temos as máscaras Mwana Phwo, Cihongo, Katoyo ou Ngulu.

Mas a máscara apenas tem significado quando alguém a usa ${ }^{8}$, pois só o binómio máscara-bailarino é portador dessas forças «sobrehumanas».

Kubik (1981) refere que a especificidade das máscaras lhes é dada pelas suas características formais e significado, mas também pelo seu posicionamento hierárquico relativamente às demais. No entanto, «Nem todos podem ser mascarados. A condição principal é ser-se homem em todo o sentido da palavra.» (Lima, 1967, p. 117), o que significa fundamentalmente ter sido submetido aos rituais da circuncisão e ensinamentos da Mukanda?

É também na Mukanda que se faz a aprendizagem das danças, estando o seu ensino à responsabilidade de um mestre (tanghixi) que transmite de forma rigorosa, os vários passos, gestos, movimentações e «estilo» das danças corres-

7 C.f. José Redinha (1965), Mesquitela Lima (1967), M.-L. Bastin (1988), Manuel Jordán (2003) e Elisabeth Cameron (1995).

$8 \mathrm{O}$ conceito de máscara não se restringe ao adereço que cobre o rosto, mas engloba igualmente o fato de rede que reveste o corpo do bailarino.

9 Instituição tradicional de iniciação masculina entre os Tucokwe, cuja função é integrar o indivíduo no conjunto dos valores da sua sociedade. 
pondentes a cada máscara. Aprender a esculpir segundo os padrões de identidade cokwe e assimilar o significado da simbologia (quase um léxico) com que «adornam»e particularizam as máscaras e demais peças, é outros dos saberes obrigatórios quando se termina este ciclo da vida entre os Tucokwe.

Os futuros bailarinos profissionais são escolhidos entre os mais talentosos, havendo casos em que a máscara - e consequentemente a profissão - é herdada de um tio, sempre irmão da mãe.

Em qualquer dos casos, devem cumprir-se na íntegra quer o processo de validação da máscara, quer o conjunto de procedimentos que permitem ao bailarino legalizar a sua condição.

\section{Os Akixi no contexto estético africano}

Na região da África central, a dança pode servir para conservar espaços culturais, através do uso codificado do corpo e do espaço, num saber transmitido de geração em geração. As máscaras são um exemplo concreto da ideia de um simbolismo complexo e multifuncional.

Como refere Kubik (1981), «Uma das regiões mais ricas em máscaras são os territórios culturalmente homogéneos compreendendo quase todo o leste de Angola, o noroeste da Zâmbia e algumas partes do Zaire.»

Sobre estas danças o mesmo autor menciona ainda que elas acontecem «em contextos sociais muito diferentes e habitualmente com funções também muito diferentes», confirmando que «existem também movimentos cujo fim é a comunicação com a audiência, incluindo algumas mensagens em código.» (ibidem)

Enquanto linguagem corporal, as danças de mascarados servem-se de estruturas de comunicação que sustentam a memória colectiva como é o caso da diversidade de gestos, posturas e alguns sinais. Assim como os símbolos, cada gesto pode ter um significado particular, apesar de reflectir as peculiaridades e propriedades do corpo que os expressa. No seu todo, esta gestualidade, enforma um conjunto de conceitos filosóficos ou ideias inerentes a um colectivo social e são usados para enviar essas mensagens morais ou de conduta.

Reportando-se à cultura Kongo, Thompson refere que: 
La perception des attitudes est d'ordre symbolique. Car la lecture des formes et du sens de la gestuelle dépend des croyances et des savoirs qui structurent la vision du monde kôngo. À ce regard, les gestes s'inscrivent dans une dialectique du dit et du non-dit, du corps hermétique et du corps ouvert, puisqu'ils recèlent des messages en même temps qu'ils les désignent à ceux qui, dans la culture kôngo, sont aptes à les décoder. (2002: 17)

Mas esta situação é igualmente válida para a cultura cokwe, entre outras da região da África central, onde a filosofia tradicional inclui certas formas de especialização do saber que se manifesta quer na dança, quer nas restantes formas de expressão.

Embora defenda que a correspondência entre linguagem e outras categorias como etnicidade, estilo, forma e uso, nem sempre se verifique, Wastiau refere que «The arts of divination, witchcraft, spirit possession and masquerading are common to most of the peoples of the region and generally indistinguishable on an ethnic basis, unless they are circumstantially designed for this purpose» (2003, p. 72), pelo que acredita na importância dos conceitos de etnicidade e tradição para o estudo das artes desta região.

Sendo a religião uma força dominante na vida e sociedades africanas, ela define fortemente a natureza da própria arte, manifestando-se com grande peso nas máscaras, cujas danças são a única manifestação de arte destinada a ser apreciada.

A este propósito (e à semelhança do que acontece na generalidade dos povos desta região), Susan Voguel (1997) refere que o povo Baulé da Costa do Marfim distingue quatro critérios para agrupar e «apreciar» as suas criações: (a) «watched», onde se integram as danças de máscaras e performances de entretenimento; (b) «seen without looking», grupo composto pelas peças e máscaras sagradas ou «terríveis» para serem vistas ao perto; (c) «glimpsed», onde estão as esculturas feitas para locais de culto, guardadas em compartimentos privados; (d) e «visible to all» integrado pelos objectos decorativos.

Entre os Tucokwe, certas máscaras são destruídas após a sua utilização. Elas podem igualmente ser dispensadas por estarem danificadas ou existir a probabilidade de se tornarem prejudiciais para o seu utilizador. Algumas têm vida efémera por serem confeccionadas com materiais perecíveis. 
Portanto, ao contrário do que se passa no Ocidente, estes objectos originais e únicos, são desvalorizados assim que a sua função está cumprida. Independentemente da sua qualidade plástica e artística, eles deixam de ter significado para a comunidade.

\section{Entre as noções de «belo» e «bom»}

Embora a arte nesta região de África não possa ser concebida separada da sua funcionalidade, também não é verdade que a sua componente plástica seja descurada.

Nestas sociedades, as diversas funções da arte podem ser detectadas através das próprias manifestações artísticas e da experiência estética que elas provocam. Assim, é possível perceber-se a arte enquanto indicador semântico (representante do complexo sistema-símbolo), enquanto agente ideológico (ilustra e manifesta princípios cosmológicos) e enquanto agente estratégico (mecanismo para a negociação social, religiosa, política ou transições económicas).

Algumas dúvidas se poderão colocar relativamente à apreciação estética da arte africana, nomeadamente se existirão padrões de «beleza» absolutos, capazes de operar transculturalmente ou se cada sociedade possui os seus próprios fundamentos estéticos.

Nestas sociedades, em que a arte também se alicerça numa base étnica, a mesma palavra significa na generalidade dos casos «belo»e «bom».

Sobre esta questão do «belo», Martínez-Ruiz diz: «I would define the African and Afro-Caribbean aesthetic by considering the idea of "beautiful" or "beauty" as a functional beauty with pragmatic significance within the cultural and social narrative. The ideas of beauty are intimately associated with cosmogonical vision, mythology, and metaphysical thinking.» (200, p. 8) Portanto, os objectos de arte são «bons» se cumprem com eficácia as funções para as quais foram destinadas, devendo simultaneamente ser agradáveis à vista, podendo falar-se de uma «beleza funcional».

Segundo Thompson, na cultura Kongo da região da Africa central, «art that brings spirit and images together is ki-mooyo, literally the idiom of the soul. (...) the concept, ki-mooyo, opens our eyes to hidden dimensions in the reinstatement of Africa objects». Thompson (1979) define ainda treze princípios capazes 
de sustentar a ideia de uma estética africana onde se destacam a «Semelhança com o ser humano», a «Luminosidade», a «Auto contenção», a «Juventude» e a «Clareza da forma», padrões tidos como fundamentais na filosofia africana, onde o ser humano e as suas qualidades são elementos centrais.

Um outro aspecto que se prende com a posição destes povos relativamente à arte, tem a ver com o facto de esta ser encarada como uma espécie de «medicina» social pela sua capacidade de proteger e defender a comunidade das «doenças sociais».

Das máscaras de dança exige-se, de forma quase imperiosa, que seja uma arte de «assombro» (Kutungumuka), ou seja, ela deve espantar e surpreender, numa dualidade entre atracção e repulsa, isto é, ela deve repelir as ameaças, os maus presságios e atrair o invisível, o que está escondido sob a morfologia dessas máscaras.

«The act of seeing means the act of being healthy, protected all the way through the process of seeing and experiencing the art.» (Martínez-Ruiz, ibidem)

Ver os akixié, na comunidade, estar perante a presença de algo extraordinário que surpreende a partir de uma experiência única e inesperada.

Ututombo, termo referido por Bastin (1989) e por Wastiau (2003) é utilizado entre os Tucokwe para expressar a noção de «belo».

Como condição para que o bailarino seja bem sucedido e reportando-se à máscara de dança Mwana Phwo, Redinha (1965) aponta a necessidade da máscara agradar, traduzindo os cânones de beleza, característicos e apreciados na mulher cokwe. Mas esta relação é recíproca: «também as mulheres são belas, quando os seus olhos recordam os olhos da máscara (...) as mulheres aprendem a graça dos seus gestos nos bailados dos bailarinos Mwana Pwo» (ibidem: 16). A morfologia dos rostos de cada máscara é naturalmente variável de acordo com o estilo do escultor obedecendo, no entanto, ao que Bastin apelida de «grammaire morphologique propre aux Tshokwe» (1989, p. 65), chegando a apontar a existência de «escolas» com opções estéticas próprias, como a do Moxico.

Como adiante veremos, as formas e as cores utilizadas na confecção das máscaras integram-se igualmente neste quadro simbólico-estético, uma vez que não são unicamente decorativas e estabelecem conexões. Entre os Tucokwe, a parte «invisível» da máscara é tão real e acessível como a sua parte material e 
visível. A sua actuação é tanto melhor quanto mais este invisível se torna perceptível, quando o intangível se torna palpável, quando a forma e o conteúdo se combinam.

\section{Um corpo revelando outro}

Para além de poder constituir uma forma identitária, o hábito de executar inscrições tegumentares como a escarificação e a pintura ou revesti-lo com uma máscara será, entre os povos, uma forma de celebrar o corpo enquanto elemento potencial exposto ao adorno, ao embelezamento ou ao prazer, mas também à religião e à magia. Viajadas no tempo através da tradição, estas práticas têm contribuído para a conservação de sistemas gráficos de significados e conteúdos complexos, como acontece entre os Tucokwe.

É a sua multiplicidade de referências, que confere à máscara a capacidade de instigar a acção da sociedade através de um vasto repertório de símbolos e desenhos. Analisando as actuações dos akixi enquanto elementos mediadores, é possível perceber-se a existência de uma relação entre essa simbologia gráfica inscrita nas esculturas, nas máscaras, no $\operatorname{corpo}^{10}$ ou nos desenhos na areia (tusona) e as figuras espaciais produzidas durante a dança. De igual modo, os gestos e as poses podem ser integrados nesse sistema simbólico geral, que incrementa e sustenta valores religiosos, rituais, institucionais e processos sociais (iniciação, estado adulto, vida e morte).

O corpo destes bailarinos é coberto por um fato de rede (civuvu), que completa a máscara, igualmente «decorado» com motivos como os losangos concêntricos (majiku) representativos do fogo ou os triângulos concêntricos (mabembe) que representam a víbora (yenge), por exemplo, transformando-se numa segunda pele.

Esses corpos em movimento põem em acção as máscaras para exaltar as características da víbora, mas também das estrelas (lutongonoxi), exibindo no rosto de madeira ou de entrecasca batida, a marca kangongo que distingue os Tucokwe dos demais. Portanto, se a presença de inscrições de ordem diversa no corpo

10 Por escarificação. 
se pode atribuir a funções exorcistas, elas podem simultaneamente dotar o indivíduo das características positivas dos seres ou entidades reproduzidos.

Este conjunto de símbolos constitui uma verdadeira linguagem onde cada marca representa uma palavra ou um grupo de palavras, uma ideia e uma filosofia.

Transportada para as máscaras de dança, esta simbologia é disposta de forma estratégica e única para a eficácia desejada. Desenhos esquemáticos do fogo, dos astros, de animais, são estrategicamente inseridos, podendo perceber-se em paralelo uma preocupação de ordem estética que nos leva a posicionar esta iconografia entre o decorativo e a mediação. É o caso da Lumba (círculo feito na face representando o sol), do traço kangongo, das masoxi (lágrimas pela dor da perda) sob os olhos, as tatuagens mipila no queixo e do motivo cruciforme cingelengele na testa, que distinguem a única máscara representante do ancestral feminino, Mukixi wa Mwana Phwo.

Relativamente ao significado das principais cores utilizadas nas máscaras cokwe, Mesquitela Lima refere que a cor branca, conseguida através da argila pemba, «é sinónimo de verdade, de justiça, de pureza, de inocência. Pode ainda significar o sol, a força, a potência e a virilidade, o homem. » (196, p. 133). Contrariamente, a cor vermelha, obtida da argila ${ }^{11}$ mukundu «significa o mal, a fraqueza, a impureza, a culpa, a mentira e ainda a lua, a mulher e a morte.» (ibidem)

Integradas no sistema cosmológico cokwe, as inscrições presentes nas grandes máscaras remetem sempre para este equilíbrio na dualidade entre o dia e a noite, entre o masculino e o feminino, entre a vida e a morte, entre o mal e o bem. Nas mais temidas como é o caso do Mukixi wa Cikungu, Mukixi wa Cikunza ou Mukixi wa Kalelwa, é notória a predominância da cor vermelha.

Relativamente aos desenhos espaciais, pode tomar-se como exemplo o círculo como figura comum nas danças africanas. Aparentemente «natural»e «espontânea», esta figura, que representa a união e a eternidade é um «symbole de vie à la fois spirituelle et temporelle» (Tierou,1989, p. 53). Para Thompson (2002), o círculo é uma representação cósmica do sol. Por outro lado, no gran-

11 Estas duas argilas (pemba e mukundu) são igualmente utilizadas para pintar os corpos dos rapazes circuncidados aquando das cerimónias de encerramento da Mukanda. 
de círculo da dança, estão subentendidos dois dos três círculos concêntricos representantes dos três níveis do saber cokwe.

Nesta disposição espacial, prevalece uma perfeita noção de territorialidade, não se registando a existência de intrusões. O espaço do grupo está perfeitamente definido (periferia), assim como o está o espaço pessoal do bailarino (todo o interior da roda).

A qualidade da performance dos akixi pode ser motivo de apreciação estética e crítica por parte daqueles que, familiarizados com as técnicas de execução das danças, estão aptos a reconhecer a capacidade e valor artísticos nos bailarinos, cujo movimento policêntrico ${ }^{12}$ deve ser bem perceptível e exímio em termos de qualidade.

Segundo Thompson, na escultura kongo a posição com um braço em cima (aponta o céu) e outro para baixo (aponta a terra, o horizonte), significa a mediação entre os antepassados e o mundo dos vivos (chão). «C'est la pose des carrefours, du croisement des routes» (2002, p. 70). Este gesto foi por mim observado numa dança de mascarados durante uma das saídas de campo que efectuei no interior de Angola, podendo servir como exemplo da grande intimidade entre a dança e a escultura.

Apresentando uma significativa variedade de formas e materiais, de representações, significados e de simbolismos ligados à fecundidade, ao cosmos, à natureza, durante a sua «actuação» estas máscaras dão vida às noções espirituais que significam.

\section{Considerações finais}

Considerando a contribuição dada para a divulgação da arte africana acontecida nos finais do século XIX e início do século XX, quer pelos coleccionadores, quer pela influência que esta teve nas obras de artistas como Picasso, Matisse ou Braque, também se pode afirmar que ela passa a ser pensada através das categorias conceituais da arte ocidental que, numa espécie de «contemplação romântica», a foi limitando às suas funções mágico-religiosas.

12 Que emana de diversos pontos do corpo ao mesmo tempo, guiados por diversos tambores (ngoma). 
Sendo evidente que o termo "estética" transporta uma carga cultural ocidental, é possível a sua utilização e ampliação no contexto da cultura africana, se o entendermos enquanto categoria qualificadora e gerindo o eventual conflito entre a subjectividade da experiência estética, experiência sensível e objectividade dos padrões e conceitos ditados e seguidos pelas culturas locais.

Como o indica o exemplo das máscaras de dança, os valores estéticos africanos mostram-se distintos dos ocidentais, já que a arte africana responde a um problema e serve uma finalidade prática. Outros fundamentos estão na origem destas diferenças, nomeadamente o facto da filosofia ou do estabelecimento da ordem serem determinados pelo contexto. Determinada pelo mesmo contexto, surge uma estética que explicita as imagens através das quais a sociedade organiza os seus próprios valores e expressa a dependência de um mundo sobrenatural.

Através da intervenção dos akixi percebe-se, pois, a arte cokwe com uma dimensão estética fundada na expressão do ritual e da religião, mas também nas marcas da personalidade deste povo. Outros factores que contribuem para esta percepção consistem no facto das máscaras existirem enquanto veículo de perpetuação e transmissão do património de uma cultura sem um sistema de escrita convencional, por um lado e serem um meio para a revitalização dos antepassados, por outro.

Na África sub-sahariana, tudo existe em correlação, residindo a essência das coisas na sua «força». Nesta zona geográfica, as pessoas alimentam uma correspondência permanente com outras forças e entidades, as quais contribuem para a unidade do grupo.

Pela sua morfologia, simbolismo ou atitude, as máscaras de dança cokwe desenvolvem, nas suas actuações, a narração ou dramatização de diversos aspectos de significado socio-cultural, através de mensagens de contornos simbólicos. $\mathrm{O}$ registo da dança enquanto forma de comunicação onde o artístico está presente faz dela a única arte para ser admirada. Aqui surgem algumas questões que levam à reconsideração sobre os conceitos de «arte» ou de «belo».

Pode dizer-se que entre os Tucokwe, as máscaras de dança fazem parte de uma estética do indizível, do domínio do que se sente e da sensação do choque (assombro) que provocam. Produzidas e dançadas por artistas que servem o culto dos antepassados, estas máscaras articulam em si o valor plástico e o seu contexto religioso. A sua missão é apresentar, personificar o «invisível». 
Retomando o ponto inicial sobre a generalização do conceito de estética africana, ficam as preocupações:

- Existe uma estética africana ou existem estéticas africanas? Apesar das afinidades artísticas da região, parece-me que esta posição deixará mais espaço para as particularidades de cada cultura ou grupo cultural.

- Nestes contextos poder-se-á adoptar o conceito de estética definida como sendo a descrição e explicação dos fenómenos artísticos através da psicologia, sociologia, etnologia ou história - sempre relacionada com a «beleza», ou será mais sensato falar-se numa estética da oralidade em que se conta com a capacidade de verbalizar os conceitos de estética, os processos criativos e as formas culturais derivadas de uma vida reflexa da oralidade e da cosmologia?

\section{Referências bibliográficas:}

ADAMS, Monni, African Visual Arts from an Art Historical Perspective, African Studies Revue, Vol 32, No 2 (Sep. 1989), p. 55 - 103

AREIA M. L. Rodrigues de, «The Chokwe in the Context of African Art», Chokwe and their Bantu Neighbours. Zurich: Galerie Walu, 2003

BAStin, Marie-Louise, ARt et Mythologie, Figures Tshokwe. Porto :Fondation Dapper ; Paris, 1988

BIEBUYCK; Daniel, African Art Studies Since 1957: Acbievements and Directions, African Studies Revue, Vol 26, No 3/4 (Sep. - Dec.1983), p. 99 - 118

BLIER, Suzanne P., Words about Words about Icons: Iconologology and the Study of African Art, Art Journal, Vol 47, № 2, Object and Intellect: Interpretations of Meaning in African art (Summer 1988), p. 75 - 87

KUBIK, Gerhard, "Música e dança a sul do Sahara", Cultural Atlas of Africa. Oxford: Phaidon, 1981, p. 90-93. Tradução e digitalização de Domingos Morais, em 1997. http:/ / attambur.com/Recolhas/PDF/MusicaDancaSahara.pdf (19.03.2003)

LIMA, Mesquitela, Os Akixi (Mascarados) do Nordeste de Angola, Lisboa, Companhia dos Diamantes de Angola, 1967

MacGAFEY, Wyatt, Aesthetics and Politics of Violence in Central Africa, Journal of African Cultural Studies, Vol 13, No 1 (Jun. 2000), pp. 63 - 75

MARTÍNEZ-RUIZ, Bárbaro, Marks of the Soul, Florida, Florida Atlantic University, 2001 
PEECK, Philip M., The Sounds of Silence: Cross-World Communication and the Auditory Arts in African Societies, American Ethnologist, Vol 21, No 3 (Aug. 1994), pp. 474 $-494$

REDINHA, José, Máscaras e Mascarados Angolanos (Uso, Formas e Ritos), Luanda,

Fundo de Turismo e Publicidade de Angola, 1965

THOMPSON, Robert Farris, African Art in Motion, Los Angeles, UCLA Art Council, 1979

THOMPSON, Robert Farris et al., Le Geste Kôngo, Paris, Éditions Dapper, 2002

TIÉROU, Alphonse, DOOPLÉ, Loi Éternelle de la Danse Africaine, Paris, Éditions Maisonneuve \& Larose, 1989

VOGEL, Susan M., African Aesthetics: The Carlo Monzino Collection, New York, Centre for African Art, 1986

VOGEL, Susan M., Baule: African Art, Western Eyes, New Haven and London: Yale University Press, 1997

WASTIAU, Boris, «Style and Ethnicity: reflections on methods for the studies of arts in the Zambezi and Kasai headwaters», A Antropologia dos Tshokwe e Povos Aparentados, Porto, Faculdade de Letras da Universidade do Porto, 2003 